\title{
Efficiency of Two Larval Diets for Mass Rearing of Aedes aegypti in Support of Sterile Insect Technique (SIT)
}

\author{
Nahida Sultana ${ }^{1}$, Mahfuza Khan ${ }^{1 *}$, Md. Rezaul Karim² and Nazma Khatun ${ }^{3}$
}

*Correspondence: mahfuza79@gmail.com

\section{CrossMark \\ «lick for updates}

\begin{abstract}
${ }^{1}$ Institute of Food and Radiation Biology, Atomic Energy Research Establishment, Ganakbari, Savar, Dhaka-1349, Bangladesh Atomic Energy Commission.

${ }^{2}$ Institute of Technology Transfer and Innovation (ITTI), Bangladesh Council of Scientific and Industrial Research, Dr. Kudrate A-Khuda Road, Dhaka- 1205, Bangladesh.

${ }^{3}$ Atomic Energy Centre, Chattogram, Bangladesh Atomic Energy Commission, Chattogram 4209, Bangladesh.
\end{abstract}

\begin{abstract}
Aedes aegypti is a major vector of arboviruses such as dengue (DENV), Chikungunya (CHIKV) and Zika (ZIKV) that may be controlled on an area-wide basis using the sterile insect technique (SIT). Larval diet is a major factor in mass-rearing for SIT programs. Accordingly, we compared dietary effects on immature development and adult fitness-related characteristics for laboratory based fish feed diet 'Super Nova' (Super Nova, Perfect Companion Group Co. Ltd., Thailand) and high quality feed for fingerlings, 'Micro-180' (Skretting, Neutreco company, USA) to use in SIT. The percentage of larvae that survived to pupation or to adult emergence did not differ significantly between the two diets under the same rearing conditions. On the second day of development, a good number of male pupae (69-71\% among total male pupae) produced from both the diet treatments. The flight ability and the longevity of Ae. aegypti did not differ significantly with larval diets, irrespective of sex. In other aspects, the 'Micro-180' diet generally performed better. Larval development was faster on the 'Micro-180' than 'Super Nova' fish feed diet. An Adult female mosquito from the 'Micro-180' diet was significantly larger and exhibited higher fecundity compared to 'Super Nova' fish feed diet. We concluded that both the diet treatments are suitable and especially the 'Micro-180' diet is likely to be more suitable for mass-rearing of Ae. aegypti for area-wide SIT-based vector control.
\end{abstract}

Keywords: Aedes aegypti, larval diets, mass rearing, quality parameters, SIT

\section{Introduction}

Aedes aegypti is the most widespread and potential vector for transmission of dengue disease [1] and this mosquito species is also responsible for spreading other vector-borne diseases like chikungunya, zika, malaria, dengue fever, encephalitis, yellow fever and filariasis $[2,3]$. Worldwide Ae. aegypti species has been identified as one of the highest invasive species $[4,5]$. For worldwide distribution of Ae. aegypti, around 2.5 billion people are at threat of dengue infection and every year approximately 50 million people are infected by dengue [1]. Ae. aegypti is well-known as a container-breeding mosquito species because it completes its aquatic immature life stage (egg to pupa) in artificial water containers or stagnant water containing natural sites of urban and suburban areas throughout the world $[6,7]$. They are exceedingly anthropophilic potential vectors and usually active at the diurnal time. The prevention of the transmission of the dengue virus can be achieved by the reduction of Ae. aegypti population because the virus transmission mostly depends on the Ae. aegypti vector.

The main tactic to reduce mosquito population is habitat eradication and mosquito breeding habitats can be treated with different chemical insecticides like larvicides and adulticides as components of the integrated way to manage mosquito population [8-10]. Therefore, chemical insecticides act as a potential and highly practiced way of control against Ae. aegypti. However, it is not only difficult but also quite impossible to eliminate all the breeding sites of Ae. aegypti. Moreover, overexposure to insecticides is associated with harmful effects on non-target 
Sultana et al. Trends in Vector Research and Parasitology 2021,

organisms of environments and mosquito populations become resistant to conventional insecticides [11]. Hence, the development of novel, innovative and effective approaches for the control of dengue vectors are immediately required to overcome the present challenge, with exact importance on methods that are environmentally friendly, cost-effective, suitable and sustainable for the integrated pest management programs $[12,13]$. Over the last few decades the Sterile Insect Technique (SIT) as a major component of area-wide integrated pest management (AW-IPM) has regained interest as a complementary tool to the current mosquito control methods to limit the transmission of mosquito-transmitted pathogens [14-17]. The SIT represents the most promising, environmentally friendly and sustainable way of mosquito control rather than other different traditional and conventional strategies. SIT is a species-specific suppressing biological method that crucially depends on mass rearing, sterilization, and release of large numbers of sterile males [18]. The consequence of releasing a huge number of sterile males to an area (which is mainly specific and separated from any other area by naturally occurring physical barrier) decreases the mosquito population level through competing wild males to mate with wild females and introduce sterility $[19,20]$. Effective control of a devastating insect population can be achieved by the systematic management of sterile insects in an AWIPM program [21,22].

However, larval diet is considered as one of the most critical and costly components of the operational running costs, in the context of applying the SIT [23]. The quality of larval diets has a direct and irreversible influence on adult qualities $[\mathbf{2 4}, \mathbf{2 5}]$, mainly on the body size of the laboratoryreared adults, and other biological functions related to their nutrition. The previous study reported that well-fed larvae become healthy and vigorous adults [26]. Quantitative and qualitative parameters of larval nutrition present significant consequences on immature longevity and development rate, which can modify population growth of mosquitoes and fix adults characteristics [27-29]. Hence, it is important to ensure that the larval diet should contain rich nutrients to escape the risk of deficiencies that might deleteriously disturb the developmental period, the rearing productivity and the vigor of the adult males produced [30]. For a successful SIT program it is important that the larval diet leads to high rearing productivity and subsequent quality of the adults produced. If the laboratory-reared adults are not compatible with the existing wild population, projected results of the SIT programs would not achieve and develop. The BLP (Bovine Liver Protein) in the IAEA standard diet worked well for the rearing of Ae. aegypti, but this is a costly ingredient and difficult to procure to many FAO and IAEA member states [31], especially in Bangladesh. Therefore, the search for other sources of larval diets and their effects on different quality parameters of mosquitoes should need to further evaluated for mass rearing of Ae. aegypti targeting SIT application.
The present study was therefore undertaken to evaluate the efficiency of the two different artificial larval diets regarding their effects on larval development and different quality parameters (viz, pupal yield (number), sex ratio, flight ability, mating capability, fecundity, percentage of egg hatch, and longevity) of Ae. aegypti under laboratory conditions. A commercial aquarium fish feed (Super Nova, Perfect Companion Group Co., Ltd) that has been regularly used to rear Ae. aegypti in our laboratory, and a high quality fingerling fish feed 'Micro-180' (Skretting, Neutreco company, USA) was used for this purpose. Experimental findings were discussed in the context of using mass reared Ae. aegypti for the application of SIT.

\section{Materials and methods \\ Mosquito culture}

The research experiment was conducted in Insect Biotechnology Division (IBD), Institute of Food and Radiation Biology (IFRB), Atomic Energy Research Establishment (AERE), Savar, Dhaka. The laboratory colony of Ae. aegypti strain was reared under controlled conditions at $27 \pm 1{ }^{\circ} \mathrm{C}, 70 \pm 10 \%$ relative humidity (RH), and photoperiod of $12 \mathrm{~h}$ light (L):12 h dark (D). To compare the effect of two larval diets on Ae. aegypti, 1000 first-instar ( 3 hours old) larvae were picked up and transferred to plastic rearing trays $(38 \times 26 \times 1.5 \mathrm{~cm})$ containing $650 \mathrm{ml}$ of water to ensure a density of 1.5 larvae per $\mathrm{ml}$ of water for maintaining optimum condition for mass-rearing of Ae. aegypti $(0.6 \pm 2.8$ larvae $/ \mathrm{ml}$ ) [32]. Each diet was supplied $(0.7 \mathrm{mg}$ diet per larva) to tray on each day up to pupation. Three replicates were maintained for each diet treatment and each parameter. All trays were checked three times a day and replaced the water if water level down due to evaporation. Larvae that turned into pupae were collected by a $3 \mathrm{ml}$ plastic pipette, recorded and placed in water containing $50 \mathrm{ml}$ beakers. The sex of pupae was manually separated according to their size (female pupae larger than male pupae). Adult mosquitoes emerged approximately after two to three days of pupation.

\section{Diets}

Two different types of fish feed used in the present study. 'Diet-1' was a high quality fingerling feed 'Micro-180' (Skretting, Neutreco company, USA). Our laboratory used commercial aquarium fish feed (Super Nova, Perfect Companion Group Co. Ltd., Thailand) was used as 'Diet-2'. Diet 1 (Micro-180) comprised of crude protein $38.0 \%$, crude fat $6.0 \%$, crude ash $11.0 \%$, crude fiber $3.0 \%$ and crude moisture $11.0 \%$. The ingredients of 'Diet 2' consisted of fish meal, wheat grain, yellow corn, rice bran, soybean meal, vitamins, minerals, food colouring, and antioxidants with protein $20.0 \%$, fat $3.0 \%$, fiber $7.0 \%$, moisture $10.0 \%$, calcium $0.7 \%$, phosphorus $0.7 \%$.

\section{Quality parameter evaluations}

The quality parameters of Ae. aegypti reared on two different diet treatments were evaluated by assessing larval duration (days), pupal yield (number), sex ratio, flight ability, mating 
capability, fecundity, percentage of egg hatching, and survival. All quality parameters were estimated and performed under the controlled laboratory condition $\left(27 \pm 1^{\circ} \mathrm{C}, 70 \pm 10 \% \mathrm{RH}\right.$, and photoperiod of $12 \mathrm{~h} \mathrm{L:12} \mathrm{h} \mathrm{D).}$

\section{Larval development and pupal yield}

Total larval period/time to pupation and time to adult emergence were calculated according to the duration of the development from the first instar larvae until the pupal formation. Survival to pupation and survival to adult emergence was determined according to the proportion of pupae that survived in relation to the total number of larvae placed in each tray. The production of male and female pupae were recorded in the duration of total pupation time in each diet treatment. The overall sex ratio was calculated as the total number of adult males in relation to the total number of adult females that emerged in each diet treatment.

\section{Body size}

Adult male and female Ae. aegypti developed from each diet treatments were stored at the deep freeze, and the size of the adults was estimated by measuring their right-wing from the distal edge of the alula to the end of the radius vein excluding fringe scales, which is a reliable indicator of body size [33]. Wings of adults were measured under-stereo microscopes. In total, 10 adults were selected for each diet to measure wing length.

\section{Flight ability}

To determine the flight ability of adults, 100 pupae were placed into a $50 \mathrm{ml}$ beaker which was introduced into tubes $(30 \mathrm{~cm} \mathrm{H}$ $\times 6 \mathrm{~cm} \mathrm{~W})$ and placed in a small cage $(33 \times 26 \times 20 \mathrm{~cm})$. Flight ability was measured according to the prevalence of adults that emerged from the pupae and were able to exit from the tube into the cage over a 48 hours period. This test was performed three times for the pupae of both diets treatments.

\section{Mating capacity}

For this purpose, 100 females and 100 males developed from both the diet treatments were separately placed inside the cages $(33 \times 26 \times 20 \mathrm{~cm})$. The mating behaviour was observed directly inside the cages over a period of two hours and the formation of a number of mating pairs was recorded. This experiment was repeated three times.

\section{Fecundity and fertility}

Males and females (100 for each) Ae. aegypti developed from each diet treatment were placed inside small cages $(33 \times 26$ x $20 \mathrm{~cm}$ ) and supplied 10\% (wt/vol) sugar solution. Poultry blood was supplied using a membrane feeding system after three days. At 24 hours after the first blood meal, a $250 \mathrm{ml}$ beaker was placed in each cage with water and a strip of white paper as an oviposition substrate. The white paper strip was removed daily and replaced by another. Eggs were counted and the fertility was measured by determining the percentage of hatching.

\section{Adult longevity}

To determine the longevity of males of each diet treatment newly emerged 100 males were selected at random, placed in a small cage $(33 \times 26 \times 20 \mathrm{~cm})$ and supplied with $10 \%$ sugar solution. Separate batches of mosquitoes from both the diet treatments were also kept with only a water supply. Each treatment was replicated three times. All dead males found each day in each replicate were counted and removed at 24 hours interval. Adult mortality was recorded daily until the last adult had died.

\section{Statistical analysis}

Data collected for larval development and quality parameters of Ae. aegypti on both the diet treatments were analyzed using Analysis of Variance (ANOVA) using Statistical Software -Minitab, USA (version-17). The graph was created in Microsoft Excel 2007.

\section{Results}

\section{Quality parameter}

The quality parameters of Ae. aegypti reared on two different diet treatments were shown in Table 1 and Figures 1-4.

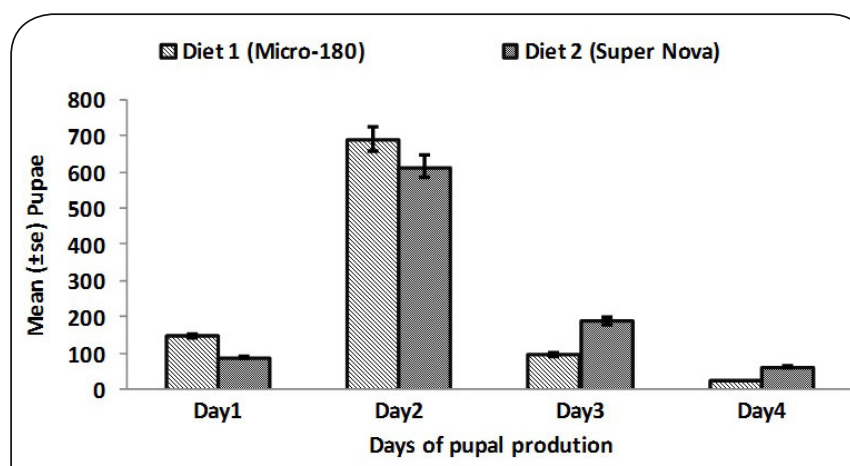

Figure 1. Mean ( \pm se) pupal production of Ae. aegypti reared on two different larval diets.

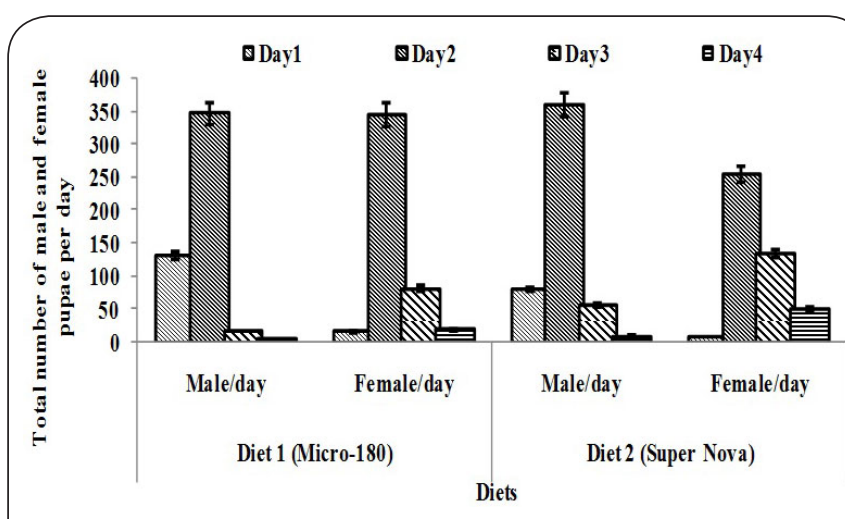

Figure 2. Total number of male and female pupal production of Ae. aegypti per day reared on two different larval diets. 
Sultana et al. Trends in Vector Research and Parasitology 2021,

http://www.hoajonline.com/journals/pdf/2054-9881-8-1.pdf

doi: $10.7243 / 2054-9881-8-1$

Table 1. Quality parameters of Ae. aegypti reared on two different larval diets.

\begin{tabular}{|c|c|c|c|}
\hline Quality Parameters & $\begin{array}{l}\text { Diet } 1 \\
\text { (Micro-180) }\end{array}$ & $\begin{array}{l}\text { Diet } 2 \\
\text { (Super Nova) }\end{array}$ & $\begin{array}{l}\text { Significance } \\
\text { (ANOVA) }\end{array}$ \\
\hline Total pupal production/pupal yield (number) & $961.5 \pm 152.82 \mathrm{a}$ & $953.5 \pm 128.77 \mathrm{a}$ & $\mathrm{d}=1,6 ; \mathrm{F}=0.00 ; \mathrm{P}=0.992$ \\
\hline Larval developmental time/Time to pupation (days) & $4.33 \pm 0.33 \mathrm{a}$ & $5.5 \pm 0.28 b$ & $\mathrm{~d}=1,4 ; \mathrm{F}=7.00 ; \mathrm{P}=0.057$ \\
\hline Adult emergence (\%) & $97.66 \pm 0.66 \mathrm{a}$ & $98.33 \pm 0.33 a$ & $\mathrm{~d}=1,4 ; \mathrm{F}=0.80 ; \mathrm{P}=0.422$ \\
\hline Sex (\% male) & $52.00 \mathrm{a}$ & $53.01 \mathrm{a}$ & $\mathrm{d}=1,4 ; \mathrm{F}=1.59 ; \mathrm{P}=0.276$ \\
\hline Flight ability (\%) & $96.0 \pm 0.28 \mathrm{a}$ & $95.1 \pm 0.44 \mathrm{a}$ & $\mathrm{d}=1,4 ; \mathrm{F}=2.50 ; \mathrm{P}=0.189$ \\
\hline Mating capacity (number of pairs) & $87.66 \pm 2.90 \mathrm{a}$ & $91.66 \pm 1.33 \mathrm{a}$ & $\mathrm{d}=1,4 ; \mathrm{F}=1.57 ; \mathrm{P}=0.279$ \\
\hline Hatching (\%) & $70.33 \pm 0.1 \mathrm{a}$ & $69.33 \pm 0.5 \mathrm{a}$ & $\mathrm{d}=1,4 ; \mathrm{F}=0.64 ; \mathrm{P}=0.468$ \\
\hline Longevity (days) & $33.00 \pm 0.57 \mathrm{a}$ & $34.16 \pm 0.44 \mathrm{a}$ & $\mathrm{d}=1,4 ; \mathrm{F}=2.58 ; \mathrm{P}=0.184$ \\
\hline
\end{tabular}

${ }^{\star}$ Means followed by the same letter are not significantly different $(\mathrm{P}>0.05)$.

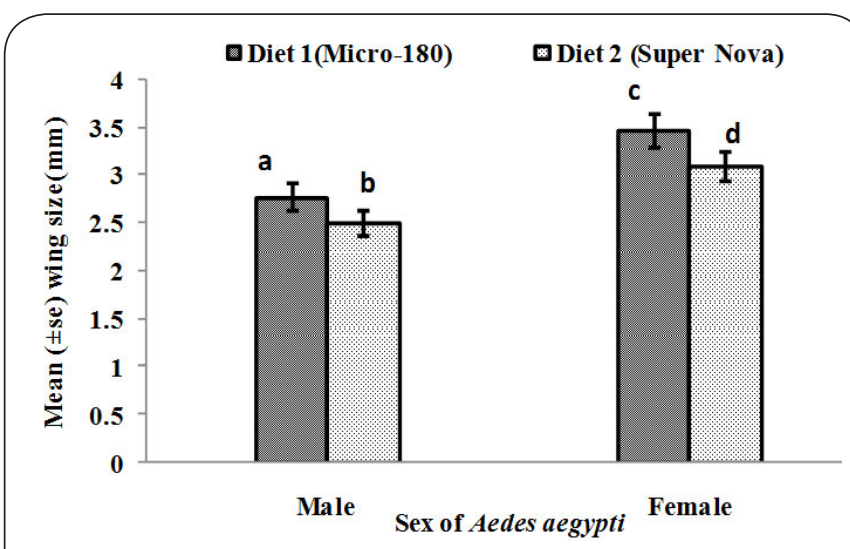

Figure 3. Mean ( \pm se) wing size of male and female Ae. aegypti reared on two different larval diets.

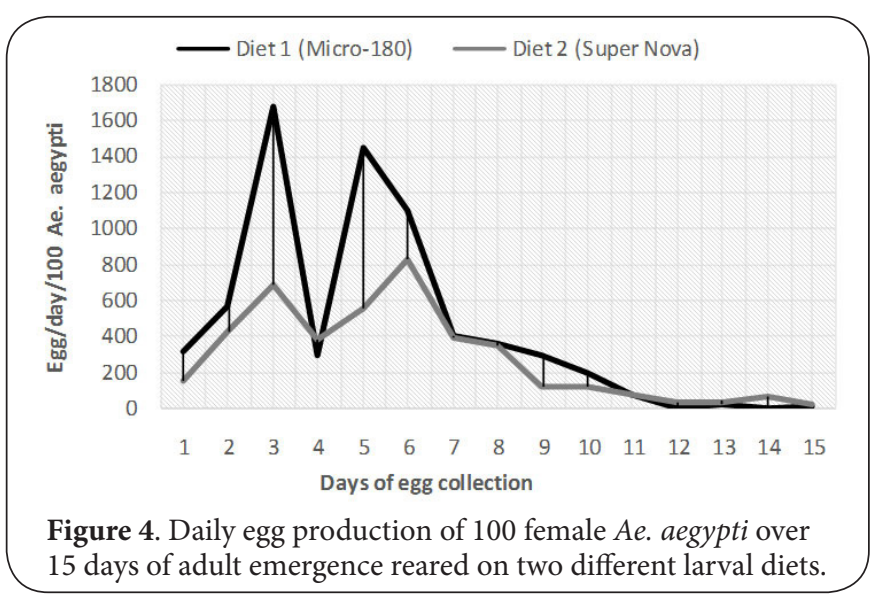

\section{Development time}

Comparatively faster larval development of $A$. aegypti i.e., first-instar larvae to first instar pupae was recorded on Diet 1 (Micro-180 diet) (mean 4.33 \pm 0.33 days) than Diet 2 (Super Nova) (5.5 \pm 0.28 days) which differed significantly ( $d=1,4$; $F=7.00 ; P=0.05)$. However, no significant differences were observed in first-instar larval stage to pupal development times between the male and female pupae on either diet. The highest number of male pupae $(69-71 \%$ among total male pupae) produced on the second day of development from both the diet treatments. Time from pupae to adult emergence (2-3 days) did not differ between the diet treatments.

\section{Production of male and female pupae}

The total pupae produced from Diet 1 and Diet 2 did not differ significantly ( $d=1,6 ; F=0.00 ; P=0.99)$ (Figure 1). Percentage of total pupal production was $96.50 \%$ and $95.35 \%$, respectively from Diet 1 (Micro-180 diet) and Diet 2 (Super Nova). Male and female pupation rate of Ae. aegypti reared on Diet 1 diet was $52.00 \%$ and $48 \%$, respectively. It was $53.01 \%$ and $46.99 \%$, respectively for those developed from Diet 2 over 4 days of total pupal production.

Comparatively more male pupae $(131.5 \pm 38.5)$ developed on the first day on Diet 1 than on Diet $2(80.5 \pm 31.5)$. But an almost similar number of male pupae developed from both the diets on the second day (347.5 \pm 71.5 and $360.5 \pm 99.5$, respectively). Comparatively greater number of females produced on the second day on Diet $1(345 \pm 33)$ than Diet $2(255 \pm 49)$ (Figure 2). Maximum number of male and female larvae pupates on the second day of development from both the diets.

\section{Body size (wing length)}

Mean wing length of males Ae. aegypti differed significantly with larval diets $(\mathrm{df}=1,18 ; \mathrm{F}=23.35 ; \mathrm{P}=0.000)$. Male wing size recorded as $2.7 \pm 0.03 \mathrm{~mm}$ from those developed from Diet 1 , and it was $2.5 \pm 0.03 \mathrm{~mm}$ for males of Diet 2 . Significantly $(\mathrm{df}=1,18 ; \mathrm{F}=13.13 ; \mathrm{P}=0.002)$ longer wing length was also recorded for females $(3.47 \pm 0.07)$ developed from Diet 1 diets than those of Diet $2(3.09 \pm 0.07 \mathrm{~mm})$ (Figure 3).

\section{Flight ability and mating capacity}

The flight ability of Ae. agepti developed from Diet 2 was 95.1 $\pm 0.44 \%$. It was similar to those of mosquitoes emerged from the Diet $1(96.0 \pm 0.28 \%)$ and did not differ significantly $(\mathrm{d}=1,4$; $\mathrm{F}=2.50 ; \mathrm{P}=0.189$ ). Comparatively less number of copulations $(87.66 \pm 2.90)$ was recorded for mosquitoes developed from 
Diet 1 than those reared on Diet $2(91.66 \pm 1.33)$ under laboratory condition although differences were not significant $(\mathrm{d}=1$, $4 ; \mathrm{F}=1.57 ; \mathrm{P}=0.279$ ).

\section{Fecundity and fertility}

The fecundity of females was measured in terms of egg production from each cage of 100 female +100 male mosquitoes over the first 15 days of adult emergence (Figure 4). The fecundity of females from the Diet 1 was 6790 eggs; 4.52 eggs/female/day) higher than females from the Diet 2 (4217; 2.81 eggs/female/day). However, the difference was not significant $(d=1,28 ; F=1.26 ; P=0.272)$. The fertility of eggs laid by females, expressed as the percentage of egg hatching, was $70 \%$ in both the diets, i.e., Diet 1 and Diet 2.

\section{Adult longevity}

The longevity of adult males maintained with water alone did not differ between diet treatments and averaged between $7.81 \pm 1.55$ and $7.25 \pm 0.03$ days. The longevity of adult males that were caged together with females with access to sugar solution also did not differ significantly between diet treatments $(\mathrm{d}=1,4 \mathrm{~F}=2.58 ; \mathrm{P}=0.184)$ with mean longevity values of $33.00 \pm 0.57$ days, and $34.16 \pm 0.44$ days on Diet 1 and Diet 2 respectively, under laboratory condition.

\section{Discussion}

A series of laboratory studies revealed that Ae. aegypti reared on Diet 1 (Micro-180) have a shorter larval developmental time, produced larger adults and greater fecundity than those developed from Diet 2 (Super Nova) (Figures 3 and 4). Generally a short pupation time and pupal development period prior to adult emergence are desirable in a mass rearing program, as these increase the overall rate of insect production. The timing of metamorphosis in Ae. aegypti larvae are known to be influenced by both the availability of food and temperature [34]. Nutritional reserves, particularly glycogen, play a regulatory role in insect development influencing the ability of larvae to pupate. In the present experiment, the pupation time from the 1st instar larval stage was shorter in Ae. aegypti reared on Diet 1 compared to Diet 2 may reflect this statement. According to Mamai et al., [31] total pupation of A. aegypti took $7.99 \pm 0.06$ days in the IAEA diet which consists of $50 \% \mathrm{TM}+$ $35 \% \mathrm{BLP}+15 \% \mathrm{BY}$ as well as in two other diets they examined using two different formulations of Black soldier fly (Hermetia illucens $\mathrm{L}$.) larvae powder. Whereas in the present study total pupation of Ae. aegypti completed within $4.33 \pm 0.33$ days using Micro-180 diet under laboratory conditions. Although longer developmental time was recorded on Diet 2 ( $5.5 \pm 0.28$ days). The present findings have some similarities with the observation of Bond et al., [35] who reported Ae. aegypti larvae fed with IAEA (IAEA 2) diet (consisted of $25 \%$ (wt/wt) bovine liver powder, $50 \%$ tuna meal, and $12.5 \%$ brewer's yeast) in dark conditions developed significantly faster (mean 3.78 days) than larvae on the Laboratory Rodent Diet (LRD) Lab Diet
5001 (PMI Nutrition International LCC, St. Louis, MO) under dark conditions (4.14 days). In the present study formation of male pupae were a bit earlier than the female pupae in both diets as recorded by Mamai et al., [31] in the case of Ae. aegypti mentioned earlier.

Usually, body size reflects nutritional status, and the level of teneral reserves in female mosquitoes is known to affect their body size, fecundity, longevity and blood meal consumption and utilization $[36,37]$. Comparatively bigger body size was observed for both the male and female Ae. aegypti reared on Diet 1 (Micro-180) than those developed from Diet 2 (Super Nova). The differences in the size of females are likely related to the greater energy content (comparatively higher carbohydrate $6 \%$ ) of the Diet 1 (Micro-180) since energy intake during the larval stage has a direct influence on the adult size in this species. It has been reported that adult teneral reserves play a vital role in the pre-vitellogenic phase of ovarian development of an autogenous mosquito [38], females use reserves carried over from the larval stage to develop the first batch of eggs. Usually, the large females are more likely to ingest more blood and lay more eggs than the small ones [39]. In the present study, comparatively larger female body size and higher egg production were recorded for $A e$. aegypti developed from Diet 1 (Micro-180) and it was 4.52 eggs/female/day over 15 days of egg collection. Whereas egg/female/day was recorded as 2.81 for Ae. aegypti reared on for Diet 2 (Super Nova). The percentage of egg hatching was almost similar on both the diet treatments. However, a bigger female size may correlate with higher fecundity and fertility of Ae. aegypti as observed in the present study may contribute to the mass production of SIT.

Studies related to the digestion of carbohydrates in mosquitoes have indicated that carbohydrates provide an important source of energy for flight and contribute to the longevity and fecundity of mosquitoes $[\mathbf{4 0 , 4 1 ]}$. The statement supports our findings where a shorter life span ( 7days) was recorded for males of Ae. aegypti has given access to water only than males that had access to sugar solution. The longevity of males (3236 days) that had access to sugar solution was almost similar and no significant differences were observed between the diet treatments $(\mathrm{d}=1,4 \mathrm{~F}=2.58 ; \mathrm{P}=0.184)$.

A larval diet for mosquitoes must provide sufficient and balanced amounts of nutrients to successfully support not only larval growth but also the production of adults of high quality. Commercial animal diet products have been historically the major components of mosquito rearing diets because they are inexpensive, more homogeneous than natural food sources, and easy to acquire and manage in large quantities [42-44]. Our study showed that the egg/female/day by $A e$. aegypti reared on the Micro-180 diets was higher compared to our Lab diet (Super Nova). Therefore, the effectiveness of the Micro-180 diet may be attributed to its high nutritional value. Although adult Ae. aegypti showed almost similar life span when reared on Diet 1 and Diet 2. Diet 1 (Micro-180) contains 
Sultana et al. Trends in Vector Research and Parasitology 2021,

http://www.hoajonline.com/journals/pdf/2054-9881-8-1.pdf

doi: $10.7243 / 2054-9881-8-1$

high amounts of proteins, fats and calcium than Diet 2 (super Nova). It is not clear how variations in each nutrient influence allocation to various mosquito functions. In this study, diet treatments did not affect the ability of mosquitoes to escape the flight tubes. The flight ability of males Ae. aegypti reared on the Micro-180 diet did not differ from those reared on Diet 2. Mating capacity in terms of copula formation was also not affected by the present diet treatments. These evaluations have important implications in the design and planning of operational SIT activities.

\section{Conclusion}

The present findings revealed that both the diet treatments, i.e., Diet 1 (Micro-180) and Diet 2 (Super Nova) could prove valuable for mass rearing of Ae. aegypti for use in SIT programs, or other types of vector control programs that require the mass-release of this species. However, the fast development and emergence of adult males before adult females (protandry) is a form of sexual selection for increased male mating opportunities via access to virgin females [58], so the search for diets that induce the expression of this trait is important. Moreover, recently the use of insects to feed insects has received tremendous response in several courtiers and become attractive as an alternative ingredient to reduce the rearing cost of different mosquito spp. In future, such an attempt should be taken to reduce the rearing cost as well as improve quality mosquitoes targeting for SIT application.

\section{Competing interests}

The authors declare that they have no competing interests.

Authors' contributions

\begin{tabular}{|l|c|c|c|c|}
\hline Authors' contributions & NS & MK & MRK & NK \\
\hline Research concept and design & -- & $\checkmark$ & -- & -- \\
\hline Collection and/or assembly of data & $\checkmark$ & -- & -- & $\checkmark$ \\
\hline Data analysis and interpretation & $\checkmark$ & $\checkmark$ & -- & $\checkmark$ \\
\hline Writing the article & $\checkmark$ & $\checkmark$ & -- & -- \\
\hline Critical revision of the article & $\checkmark$ & $\checkmark$ & $\checkmark$ & -- \\
\hline Final approval of article & $\checkmark$ & $\checkmark$ & $\checkmark$ & $\checkmark$ \\
\hline Statistical analysis & -- & $\checkmark$ & -- & -- \\
\hline
\end{tabular}

\section{Acknowledgements}

The authors would like to thank Mr. Md. Abdus Salam, Senior Scientific Assistant, Insect Biotechnology Division, Institute of Food and Radiation Biology for the maintenance of the stock colony of Ae. aegypti.

Publication history

Editor: Werner Apt Baruch, University of Chile, Holland.

Received: 12-Dec-2020 Final Revised: 28-Feb-2021

Accepted: 16-Mar-2021 Published: 21-Mar-2021

\section{References}

1. WHO: Dengue guidelines for diagnosis, treatment, prevention and control: new edition. 2009 , World Health Organization. Available from: https://apps.who.int/iris/handle/10665/44188
2. WHO: World Health Organization. 2017, Available from: http://www.who. int/mediacentre/factsheets/zika/en/ and http://www.who.int/mediacentre/factsheets/fs327/en/.

3. Weaver SC and Reisen WK: Present and future arboviral threats. Antiviral Res. 2010, 85:328-345. doi: 10.1016/j.antiviral.2009.10.008

4. Gratz NG: Critical review of the vector status of Aedes albopictus. Med. Veter. Entomol. 2004, 18(3): 215-227.

5. Medlock JM, Hansford KM, Schaffner F, Versteirt V, Hendrickx G, Zeller $\mathrm{H}$ and Bortel WV: A review of the invasive mosquitoes in Europe: ecology, public health risks, and control options. Vector-Bor. Zoon. Dis. 2012, 12(6): 435-447.

6. Barrera R: Competition and resistance to starvation in larvae of container inhabiting Aedes mosquitoes. Ecol. Entomol. 1996, 21(2):117-127.

7. Scott T, Morrison A, Lorenz L, Clark G, Strickman D and Kittayapong P: Longitudinal studies of Aedes aegypti (Diptera: Culicidae) in Thailand and Puerto Rico: population dynamics. J. Med. Entomol. 2000, 32:77-88.

8. Curtis CF and Hill N: Comparison of methods of repelling mosquitoes. Entomol. Exp. Appl. 1988, 49:(1-2):175-179.

9. Tikar SN, Yadav R, Mendki MJ, Rao AN, Sukumaran D, and Parashar BD: Oviposition deterrent activity of three mosquito repellents diethyl phenyl acetamide (DEPA), diethyl $m$ toluamide (DEET), and diethyl benzamide (DEB) on Aedes aegypti, Aedes albopictus, and Culex quinquefasciatus. Parasit. Res. 2014, 113(1):101-106.

10. Xue RD, Barnard DR and Ali A: Laboratory and field evaluation of insect repellents as oviposition deterrents against the mosquito Aedes albopictus. Med. Vet. Entomol. 2001, 15(2):126-131.

11. Karunamoorthi $\mathrm{K}$ and Sabesan $\mathrm{K}$ : Insecticide resistance in insect vectors of disease with special reference to mosquitoes: a potential threat to global public health. Health Sco. Int. Quart. J. 2013, 2: 4-18.

12. Service MW: Importance of ecology in Aedesaegypti control. Southeast Asian J. Trop. Med. Pub. Heal. 1992, 23:681-690.

13. Swaddiwudhipong W, Lerdlukanavonge $P$, Khumklam P, Koonchote $S$, Nguntra $P$, and Chaovakiratipong C: A survey of knowledge, attitude and practice of the prevention of dengue hemorrhagic fever in an urban community of Thailand. Southeast Asian J. Trop. Med. Pub. Heal. 1992, 23:207-211.

14. Bellini R, Medici A, Puggioli A, Balestrino F, and Carrieri M: Pilot field trials with Aedes albopictus irradiated sterile males in Italian urban areas. $J$. Med. Entomol. 2013, 50: 317-325.

15. Gilles JRL, Schetelig MF, Scolari F, Marec F, Capurro ML. Franz G and Bourtzis K: Towards mosquito sterile insect technique programmes: exploring genetic, molecular, mechanical and behavioural methods of sex separation in mosquitoes. Acta Tropi. 2014,132S: S178-S187.

16. Lees R, Gilles J, Hendrichs J, Vreysen M and Bourtzis K: Back to the future: the sterile insect technique against mosquito disease vectors. Current Opin. Insect Sci. 2015,10: 156-162.

17. Pleydell $D$ and Bouyer J. Biopesticides improve efficiency of the sterile insect technique for controlling mosquito-driven dengue epidemics. Commun. Biol. 2019, 2: 201.

18. Lee SS, Baker RE, Gaffney EA and White SM.: Modeling Aedes aegypti mosquito control via transgenic and sterile insect techniques: endemics and emerging outbreaks. J. Theor. Biol. 2013, 331: 78-90. https://doi. org/10.1016/j.jtbi.2013.04.014.

19. Lees RS, Gilles JRL, Hendrichs J, Vreysen MJB and Bourtzis K: Back to the future: the sterile insect technique against mosquito disease vectors. Curr. Opin. Ins. Sci. 2015, 10: 156-162.

20. Dyck VA, Hendrichs J and Robinson AS: Sterile insect technique principles and practice in area-wide integrated pest management. Netherlands: Springer, 2005, 787.

21. Knipling EF: Possibilities of insect control or eradication through the use of sexually sterile males. J. Econ. Entomol. 1955, 48(4): 459-462.

22. Hendrichs, J and Robinson AS: Sterile insect technique. In: Resh VH and Carde RT (Eds.), Encyclopedia of Insects. Burlington, MA, Academic, 2nd edn., 2009, 1074-1078.

23. Gingrich R, Graham A and Hightower B: Media containing liquefied nutri- 
ents for mass-rearing larvae of the screw-worm. J. Econ. Entomol. 1971, 64: 678-683.

24. Briegel $\mathrm{H}$ and Timmermann SE: Aedes albopictus (Diptera: Culicidae): physiological aspects of development and reproduction. J. Med. Entomol. 2001, 38(4):566-571.

25. Benedict MQ, Knols BG, Bossin HC, Howell PI, Mialhe E, Caceres C and Robinson AS: Colonisation and mass rearing: learning from others. Malar. J. 2009, 8(2): S4.

26. Zeller $\mathrm{M}$ and Koella JC: Effects of food variability on growth and reproduction of Aedes aegypti. Ecol. Evol. 2016, 6: 552-559. doi: 10.1002/ ece3.1888

27. Barrera R, Amador M and Clark GG: Ecological factors influencing Aedes aegypti (Diptera: Culicidae) productivity in artificial containers in Salinas, Puerto Rico. J. Med. Entomol. 2006, 43: 484-492. doi: 10.1093/jmedent/43.3.484

28. Araújo M, Gil LH and e-Silva A: Larval food quantity affects development time, survival and adult biological traits that influence the vectorial capacity of Anopheles darlingi under laboratory conditions. Malar. J. 2012, 1:261. doi: 10.1186/1475-2875-11-261

29. Li Y, Kamara F, Zhou G, Puthiyakunnon S, Li C and Liu Y. et al.: Urbanization increases Aedes albopictus larval habitats and accelerates mosquito development and survivorship. PLoS Negl. Trop. Dis 2014, 8:e3301. doi: 10.1371/journal.pntd.0003301

30. Timmermann SE and Briegel $\mathrm{H}$ : Larval growth and biosynthesis of reserves in mosquitoes. J. Insect Physiol. 1999, 45(5): 461-470.

31. Mamai W, Bimbil eSomda NS, Maiga H, Konczal A, Wallner T, Bakhoum MT, Yamada H. and Bouyer J: Black soldier fly (Hermetiaillucens) larvae powder as a larval diet ingredient for mass-rearing Aedes mosquitoes. Paras. 2019, 26: 57.

32. Bargielowski I, Nimmo D, Alphey L and Koella JC: Comparison of life history characteristics of the genetically modified OX513A line and a wild type strain of Aedes aegypti. PLoS One. 2011, 6: e20699. https:// doi. org/10.1371/journal.pone.0020699

33. Marina CF, Arredondo-JimeÂnez JI, Castillo A and Williams T: Sublethal effects of iridovirus disease in a mosquito. Oecol. 1999, 119: $383 \pm 388$. https://doi.org/10.1007/s004420050799.

34. Chambers GM and Klowden MJ: Correlation of nutritional reserves with a critical weight for pupation in larval Aedes aegypti mosquitoes. J. Am. Mosq. Cont. Ass. 1990, 6: 394-399.

35. Bond JG, RamõÂrez-Osorio A, Marina CF, FernaÂndez-Salas I, Liedo P, Dor $A$, and Williams T: Efficiency of two larval diets for mass-rearing of the mosquito Aedes aegypti. PLoS One. 2017, 12(11): e0187420. https://doi. org/10.1371/journal. pone.01874205446.

36. Briegel H.: Fecundity, metabolism, and body size in Anopheles (Diptera: Culicidae), vectors of malaria. J. Med. Entomol. 1990, 27: 839-850.

37. Naksathit AT and Scot W: Effect of female size on fecundity and survivorship of Aedes aegypti fed only human blood versus human blood plus sugar. J. Ame. Mosq. Cont. Ass. 1998, 14: 148-152.

38. Telang $A$, Li $Y$, Noriega $F$ and Brown $M$ : Effects of larval nutrition on the endocrinology of mosquito egg development. J. Exp. Biol. 2006, 209: 645-655.

39. Takken W, Klowden M and Chambers G: Effect of body size on host seeking and blood meal utilization in Anopheles gambiaesensustricto (Diptera: Culicidae): the disadvantage of being small. J. Med. Entomol. 1998, 35: 639-645.

40. Van Handel E: The obese mosquito. J. Physiol. 1965, 181: 478-486.

41. Clements AN: The source of energy for flight in mosquitoes. J. Exp. Biol. 1965, 32: 547-554.

42. Benedict MQ, Knols BGJ, Bossin HC, Howell PI Mialhe E and Caceres C. et al,: Colonization and mass rearing: learning from others. Malar. J. 2009, 8: S4.

43. Damiens $D$, Benedict $M Q$, Wille $M$ and Gilles JRL: An inexpensive and effective larval diet for Anopheles arabiensis (Diptera: Culicidae): eat like a horse, a bird, or a fish. J. Med. Entomol. 2012, 49: 1001-1011.

44. Gerberg EJ : Manual for mosquito rearing and experimental techniques. Am. Mosq. Cont. Assoc. Bull. 1970, 5: 1-109.

\section{Citation:}

Sultana N, Khan M, Karim R and Khatun N. Efficiency of Two Larval Diets for Mass Rearing of Aedes aegypti in Support of Sterile Insect Technique (SIT). Trends Vector Res Parasitol. 2021; 8:1. http://dx.doi.org/10.7243/2054-9881-8-1 